\title{
Fuzzy vision
}

\section{A dark view of a future where the lines of self are blurred.}

\section{Tomorrow's People: How 21st Century Technology is Changing the Way We Think and Feel \\ by Susan Greenfield \\ Allen Lane: 2003.304 pp. $£ 20$}

\section{Melvin Konner}

It is best to be frank: when a boy from Brooklyn reviews a book by a baroness, there is, let us say, some trepidation. When the baroness is also a distinguished Oxford neuroscientist and director of the Royal Institution of Great Britain, self-confidence suffers further. Add to this the indisputable fact that (as the author points out) the reviewer is "hormonally challenged" by virtue of being male, and you have a serious set of obstacles. Nevertheless, one must try.

Susan Greenfield, author of The Private Life of the Brain, has here turned her skilled attention, intellectual power and literary gifts to the world to come. Baseball star Yogi Berra held that it is very difficult to make predictions, especially about the future. However, a large academic and industrial network worldwide is devoted to just such predictions. Trillions of euros are riding on them, and that prize, along with intrinsic human curiosity, underwrites the quest for believable visions of how we will live twenty, fifty or even a hundred years from now.

Greenfield's book is, first of all, a survey of the most plausible of those visions, sifted through the judgement of a wise and experienced scientist. If you want to know what sort of house you are likely to live in, how you will work, commute and communicate, and what you will do to monitor your health, you will find answers here that are the products of a rich imagination, but one informed by a broad knowledge of the cutting edge of technology and the aspirations of scientists and inventors working that frontier. The presentation is blessedly low on the gee-whiz, breathless style of much futurist writing, and avoids unreflective enthusiasm as carefully as it steers clear of luddite technophobia.

Some scenarios are both engaging and unsettling. Vast armies of nanorobots will do our bidding, while neuron-silicon interfaces blur the edge of the self. Computer chips will make every object we handle smart, adaptive, personalized and self-sustaining. Work will disappear into part-time efforts at home. Our bodies and their products will be automatically tested daily for hundreds of diseases, and the walls will light up with lucid explanations of signs, symptoms, diagnosis and treatment. We may relax in the evening by summoning a three-dimensional, virtual, life-sized sitcom that unfolds around us.

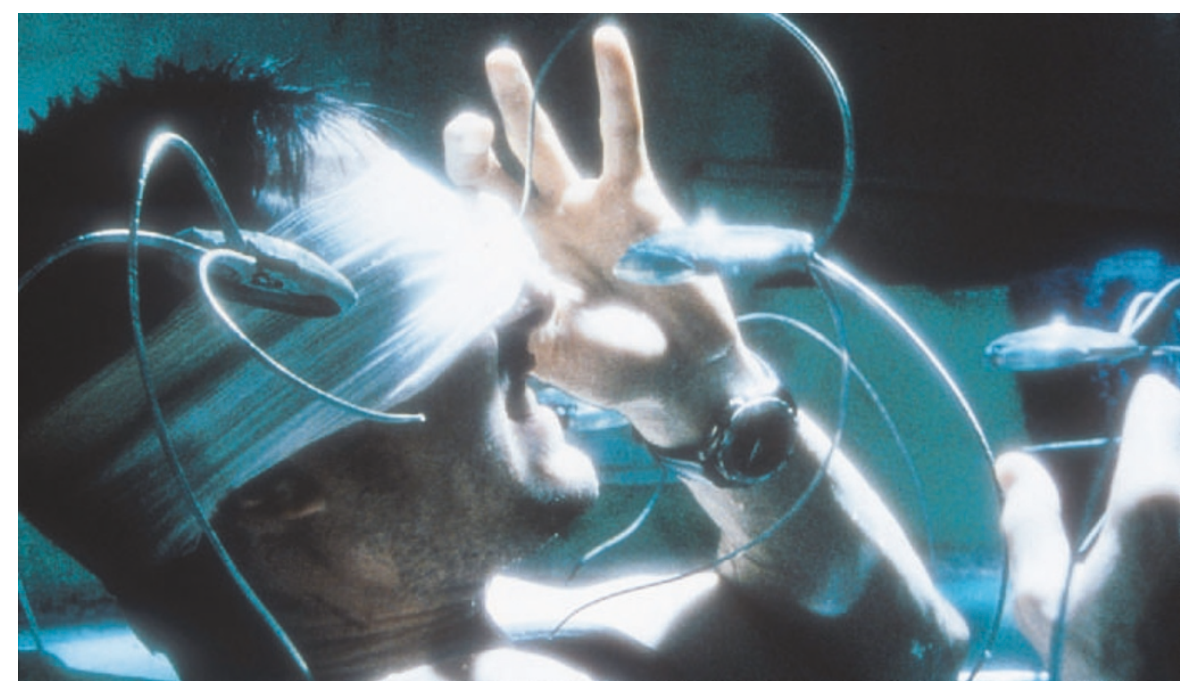

No hiding place: Tom Cruise tries to cover up his identity in the dystopian future of Minority Report.

Sex will be solitary, technologically assisted, varied enough to match our wildest fantasies, and unbelievably satisfying. Genes, of course, will be shaped at or before conception. Enhancement drugs will homogenize our minds, and generic, synthetic bacteria will be stored for a thousand uses determined by changing their genomes at the touch of a button - or, more likely, at a word. The first half of the book consists mainly of such revelations - some surprising, some familiar, but all thought-provoking.

The second half of the book is more important and more problematic. Here Greenfield deals with the human implications of these predicted advances. A chapter on education is sensible but fairly conventional; it demonstrates the impact of experience on the brain, suggesting that it will remain the best route to improving that organ. A clear discussion of consciousness and the brain brings the reader to the frontier of knowledge, but wisely does not attempt to solve the problem, instead simply intimating that consciousness itself will change in ways that have something to do with silicon.

In the remaining chapters on terrorism and human nature, followed by a brief concluding essay on our options, readers may become confused as to where Greenfield stands. She has declared herself no technophobe, but raises some ominous possibilities, and in the end she sounds an alarm. She quotes Bertrand Russell: "Science has not given men more self-control, more kindliness, or more power of discounting their passions... Men's collective passions are mainly evil; far the strongest of them are hatred and rivalry directed toward other groups." And there is Freeman Dyson: "In the long run, the central problem of an intelligent species is the problem of sanity." Greenfield does not seem to think that the science of the future will change human nature, and her opinion of our nature, though not as dark as Russell's, is not encouraging.

Science, she points out, will place unprecedented power in the hands of terrorists. Cyber-attacks could make processed food toxic by manipulating manufacturers' computers from half-way around the world. Bacteria could be designed to target the genetic vulnerabilities of a particular race. Hackers could bring whole nations to a halt. Human nature (along with its seven deadly sins) being in all likelihood unchanging, future science's brave new world could easily be far more dangerous than our own.

In the final pages, Greenfield considers the great majority of humanity who are likely to be left outside the new world. She writes of a science 'peace corps' that would somehow make this world and its advantages universal. But no less an authority on future technology than Bill Gates has doubts. At a conference on bringing technology to the developing world, he envisaged an African village with a computer: "The mothers are going to walk right up to that computer and say, 'My children are dying, what can you do?' Do you really have to put in computers to figure that out?" Gates has invested his vast philanthropic resources in vaccination and other basic public-health measures, not in 'siliconizing' Africa.

In the end, Greenfield writes: "The bottom line of this book is that the private ego is the most precious thing we each have, and it is far more vulnerable now than ever before." The ultimate priority, she continues, should be "not just the preservation, but also the 
celebration of individuality". It ends with a warning: "Time could be running out" on our options, and "we may be the last generation of individuals able, or willing, to have them."

Greenfield almost seems, in the course of the book, to have turned into something of a technophobe. In any case, she leaves the reader feeling ambivalent about the wisdom of pushing technology rapidly, relentlessly and often rather thoughtlessly forwards.

Melvin Konner is in the Department of

Anthropology, Emory University, Atlanta, Georgia 30322, USA. He is the author of The Tangled Wing: Biological Constraints on the Human Spirit, revised edition.

$\bullet \bullet \bullet \bullet \bullet \bullet \bullet \bullet \bullet \bullet \bullet \bullet \bullet \bullet \bullet \bullet \bullet \bullet \bullet \bullet \bullet \bullet \bullet$ Jazzing up

\section{neuroscience}

\section{The Cognitive Neuroscience}

\section{of Music}

edited by Isabelle Peretz \& Robert Zatorre

Oxford University Press: 2003. 466 pp.

$\mathfrak{E} 75, \$ 124.50$ ( $h b k$ ); $\mathfrak{E 3 4 . 9 5 , ~ \$ 5 9 . 5 0 ~ ( p b k ) ~}$

\section{Petr Janata}

From the soothing lyrical quality of lullabies to the driving pulse of techno, humans render sound patterns in myriad ways to serve diverse purposes. One category of human-generated sound patterns - speech - has the clear purpose of communication and has received considerable scientific attention. But the purpose of another immense range of sound patterns - those that underlie music - is manifold and mysterious. Compared with language, it has been difficult to ascribe to music a dominant role or specific survival value. Perhaps this is why there has been little effort to study the neural processes that underlie it.

The Cognitive Neuroscience of Music, a collection of chapters that originated from a meeting of the NewYork Academy of Sciences in May 2000, announces the arrival of music at the frontiers of neuroscience. Perhaps unsurprisingly, it begins by addressing allegations that searching for a biological basis for music is futile because music has no apparent adaptive role in human evolution. However, beyond this opening salvo and two chapters explicitly devoted to comparing music and language, the cognitive neuroscience of music is explored on its own merits.

The major strength of this multiauthored volume is that it captures the breadth of the field and introduces a diverse array of behavioural and cognitive neuroscience techniques, providing several perspectives on what music is and how it might be studied. For example, many authors use a bottom-up approach to focus on the neural correlates of the perception and production of individual tones (and their various qualities such as

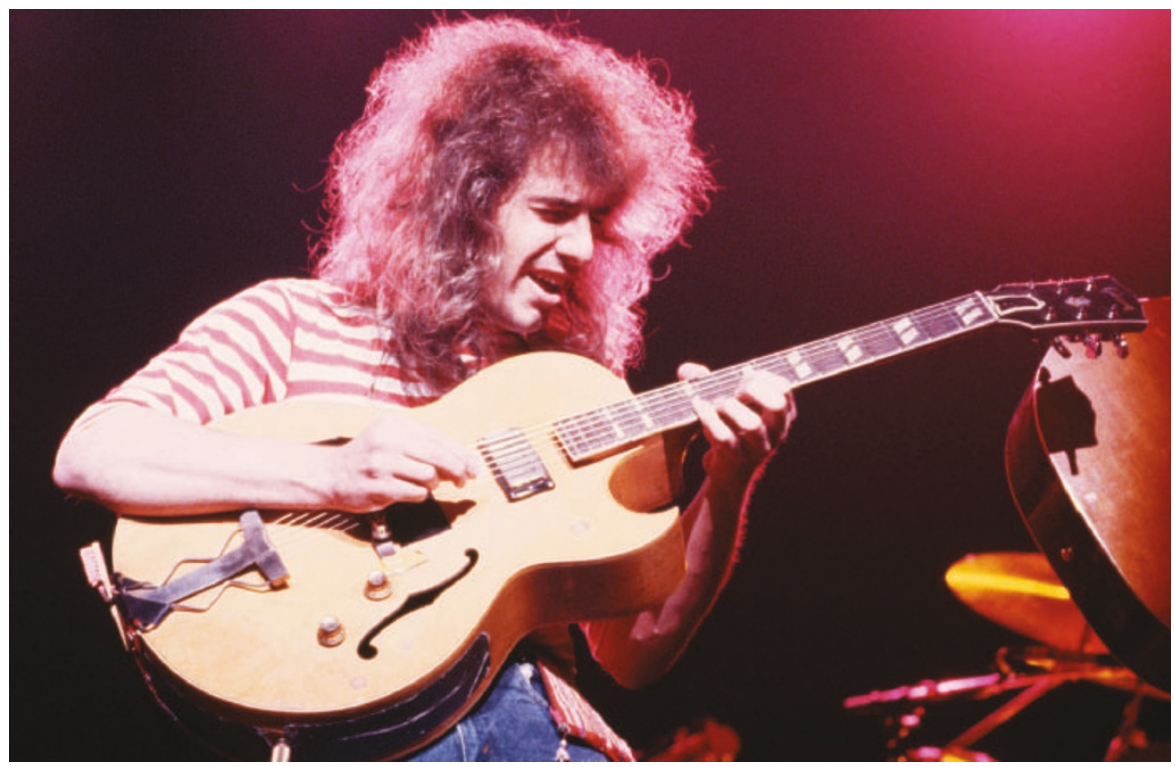

Nice! But what happens to the brain when Pat Metheny hits the right notes?

pitch, timbre, loudness and duration), and ultimately on combinations or sequences of tones in various rhythmic patterns. Although they do not necessarily capture the essence of music, such studies of its building blocks are important because they help to identify how musical percepts arise and how they are ultimately differentiated from general multipurpose auditory perception.

Other approaches emphasize the importance of the higher-order structural relationships in music, such as scales, keys and musical phrases, to illustrate that even infants and non-musicians readily internalize such structures when they form memories and images of musical material. Yet other research programmes used expert musicians, with their highly specialized knowledge, in comparative studies of brain anatomy and functional organization, thereby examining an ethologically valid model of brain plasticity in humans.

Unfortunately, the benefits of these multiple viewpoints are diminished by the variation in presentation style. Some chapters, such as those that describe neurological disorders, musical imagery, the processing of expectations in music and language, and the evolutionary basis of music, are written for the lay reader and are a pleasure to read; other chapters have the density of conference proceedings aimed at the specialist. Although the chapters are grouped logically into several themes, the reader is left to stitch the information together across chapters and themes.

The heterogeneity that makes the reading difficult at times is akin to the free improvization of a jazz ensemble before it revisits the recognizable and coherent theme at the head of a piece. Just as a jazz guitarist's improvization follows a coherent path that may be different from the bass player's, the findings from the individual research programmes represented in this book are intriguing and internally consistent, even though their interrelationships may not be obvious. For instance, there is no conceptual framework that reconciles observations of anatomical specificity, or 'modularity', of musical function (arising from neuropsychological assessments of lesion patients) with the variability in the networks that are recruited during musical tasks (as observed in functional neuroimaging experiments).

There has been a doubling in the number of music-related cognitive-neuroscience citations in the Science Citation Index since the conference was held that gave rise to this book. As the themes laid out here are revisited and elaborated on by the numerous players joining in the scientific jam session, the glorious moment will certainly come when all the themes blend into a harmonious whole.

Petr Janata is in the Department of Psychological and Brain Sciences, and at the Center for Cognitive Neuroscience, Dartmouth College, Hanover, New Hampshire 03755, USA.

\section{$\cdots \cdots \cdots$ Looking for a new home?}

\section{New Worlds in the Cosmos:}

The Discovery of Exoplanets

by Michel Mayor \& Pierre-Yves Frei (transl. Boud Roukema)

Cambridge University Press: 2003. 248 pp.

$\mathfrak{1} 18.95, \$ 30$

\section{Alan Boss}

In 1995, Michel Mayor and Didier Queloz presented the first solid evidence for the existence outside our own Solar System of a planetary-mass body orbiting a Sun-like star. The number of likely extrasolar planets has since grown to more than 100 , and both 